\title{
Elevation of troponin I in acute ischemic stroke
}

Yu-Chin Su, Kuo-Feng Huang, Fu-Yi Yang, Shinn-Kuang Lin

Background. Cardiac morbidities account for $20 \%$ of deaths after ischemic stroke and is the second commonest cause of death in acute stroke population. Elevation of cardiac troponin has been regarded as a prognostic biomarker of poor outcome in patients with acute stroke.

Methods. This retrospective study enrolled 871 in-patients with acute ischemic stroke from August 2010 to March 2015. Data included vital signs, laboratory parameters collected in the emergency department, and clinical features during hospitalization. National Institutes of Health Stroke Scale (NIHSS), Barthel index, and modified Rankin Scale (mRS) were used to assess stroke severity and outcome.

Results. Elevated troponin I $(\mathrm{Tnl})>0.01 \mu \mathrm{g} / \mathrm{L}$ was observed in $146(16.8 \%)$ patients. Comparing to patients with normal Tnl, patients with elevated Tnl were older (median age 77.6 years vs 73.8 years), had higher median heart rates ( $80 \mathrm{bpm}$ vs $78 \mathrm{bpm}$ ), higher median white blood cells (8.40 vs $\left.7.501000 / \mathrm{m}^{3}\right)$ and creatinine levels $(1.40 \mathrm{mg} / \mathrm{dL}$ vs 1.10 $\mathrm{mg} / \mathrm{dL}$ ), lower median hemoglobin ( $13.0 \mathrm{~g} / \mathrm{dL}$ vs $13.7 \mathrm{~g} / \mathrm{dL}$ ) and hematocrit (39\% vs $40 \%$ ) levels, higher median NIHSS scores on admission (11 vs 4 ) and at discharge (8 vs 3), higher median mRS scores (4 vs3) but lower Barthel index scores (20 vs 75) at discharge $(\mathrm{p}<0.001)$. Multivariate analysis revealed that age $\geqq 76$ years (OR 2.25, $\mathrm{Cl}$ 1.59-3.18), heart rate $\geqq 82$ bpm (OR 1.47, Cl 1.05-2.05), evidence of clinical deterioration (OR 9.45, Cl 4.27-20.94), NIHSS score $\geqq 12$ on admission (OR 19.52, Cl 9.59-39.73), and abnormal Tnl (OR 1.98, Cl 1.18-3.33) were associated with poor outcome. Significant factors for inhospital mortality included male gender (OR 3.69, $\mathrm{Cl}$ 1.45-9.44), evidence of clinical deterioration (OR 10.78, Cl 4.59-25.33), NIHSS score $\geqq 12$ on admission (OR 8.08, Cl 3.0421.48), and elevated $\mathrm{Tnl}$ level (OR 5.59, $\mathrm{Cl}$ 2.36-13.27). C-statistics revealed that abnormal Tnl improved the predictive power of both poor outcome and in-hospital mortality. Addition of $\mathrm{Tnl}>0.01 \mathrm{ug} / \mathrm{L}$ or $\mathrm{Tnl}>0.1 \mathrm{ug} / \mathrm{L}$ to the model-fitting significantly improved $c$-statistics for in-hospital mortality from 0.887 to $0.926(p=0.019)$ and $0.927(p=0.028)$, respectively.

Discussion. Elevation of Tnl during acute stroke is a strong independent predictor for both poor outcome and in-hospital mortality. Careful investigation of possible concomitant cardiac disorders is warranted for patients with abnormal troponin levels. 


\section{Elevation of Troponin I in Acute Ischemic Stroke}

2

3 Yu-Chin Su ${ }^{1}$, Kuo-Feng Huang ${ }^{2,3}$, Fu-Yi Yang ${ }^{1}$, Shinn-Kuang Lin ${ }^{1,3}$

4

$5 \quad{ }^{1}$ Stroke Center and Department of Neurology, Taipei Tzu Chi Hospital, Buddhist Tzu Chi

6 Medical Foundation, New Taipei City, Taiwan

$7 \quad{ }^{2}$ Department of Surgery, Division of Neurosurgery, Taipei Tzu Chi Hospital, Buddhist Tzu Chi

8 Medical Foundation, New Taipei City, Taiwan

$9 \quad{ }^{3}$ School of Medicine, Tzu Chi University, Hualien, Taiwan

13 Corresponding Author:

14 Shinn-Kuang Lin ${ }^{1,3}$

15 No 289, Jian Guo Road, Sindian district, New Taipei City, 231, Taiwan

16 E-mail: jy0428@totalbb.net.tw; sk2022@tzuchi.com.tw

17 
19

20

21

22

\section{Abstract}

Background. Cardiac morbidities account for $20 \%$ of deaths after ischemic stroke and is the second commonest cause of death in acute stroke population. Elevation of cardiac troponin has been regarded as a prognostic biomarker of poor outcome in patients with acute stroke.

Methods. This retrospective study enrolled 871 in-patients with acute ischemic stroke from August 2010 to March 2015. Data included vital signs, laboratory parameters collected in the emergency department, and clinical features during hospitalization. National Institutes of Health Stroke Scale (NIHSS), Barthel index, and modified Rankin Scale (mRS) were used to assess stroke severity and outcome.

Results. Elevated troponin I $(\mathrm{TnI})>0.01 \mu \mathrm{g} / \mathrm{L}$ was observed in $146(16.8 \%)$ patients.

Comparing to patients with normal TnI, patients with elevated TnI were older (median age 77.6 years vs 73.8 years), had higher median heart rates ( $80 \mathrm{bpm}$ vs $78 \mathrm{bpm}$ ), higher median white blood cells (8.40 vs $\left.7.501000 / \mathrm{m}^{3}\right)$ and creatinine levels $(1.40 \mathrm{mg} / \mathrm{dL}$ vs $1.10 \mathrm{mg} / \mathrm{dL})$, lower median hemoglobin (13.0 g/dL vs $13.7 \mathrm{~g} / \mathrm{dL})$ and hematocrit (39\% vs 40\%) levels, higher median NIHSS scores on admission (11 vs 4) and at discharge (8 vs 3), higher median mRS scores (4 vs3) but lower Barthel index scores $(20$ vs 75$)$ at discharge $(p<0.001)$. Multivariate analysis revealed that age $\geqq 76$ years (OR 2.25, CI 1.59-3.18), heart rate $\geqq 82$ bpm (OR 1.47 , CI 1.05-2.05), evidence of clinical deterioration (OR 9.45, CI 4.27-20.94), NIHSS score $\geqq 12$ on admission (OR 19.52, CI 9.59-39.73), and abnormal TnI (OR 1.98, CI 1.18-3.33) were associated with poor outcome. Significant factors for in-hospital mortality included male gender (OR 3.69, CI 1.45-9.44), evidence of clinical deterioration (OR 10.78, CI 4.59-25.33), NIHSS score $\geqq 12$ on admission (OR 8.08, CI 3.04-21.48), and elevated TnI level (OR 5.59, CI 2.3613.27). $C$-statistics revealed that abnormal TnI improved the predictive power of both poor 
42 outcome and in-hospital mortality. Addition of $\mathrm{TnI}>0.01 \mathrm{ug} / \mathrm{L}$ or $\mathrm{TnI}>0.1 \mathrm{ug} / \mathrm{L}$ to the model-

43 fitting significantly improved $c$-statistics for in-hospital mortality from 0.887 to $0.926(p=0.019)$

44 and $0.927(p=0.028)$, respectively.

45 Discussion. Elevation of TnI during acute stroke is a strong independent predictor for both poor

46 outcome and in-hospital mortality. Careful investigation of possible concomitant cardiac

47 disorders is warranted for patients with abnormal troponin levels.

49 Key words: troponin I; acute ischemic stroke; cardiac enzyme; poor outcome; in-hospital

50 mortality 
61

62

63

64

65

66

67

68

69

70

71

72

73

74

75

76

77

\section{Introduction}

2 Heart disease and stroke are the second and third leading causes of death after cancer in Taiwan. Cerebrovascular and coronary artery diseases share many of the same risk factors.

Cardiac mortality accounts for $20 \%$ of deaths and is the second commonest cause of death in the acute stroke population, second only to neurologic deaths as a direct result of the incident stroke (Bounds et al., 1981; Prosser et al., 2007). Prevalence of symptomatic and asymptomatic ischemic heart disease in acute stroke has been reported to be 20 to $30 \%$ and $40 \%$, respectively (Adams et al., 2003). Cardiac troponins are important biomarkers of acute myocardial infarction and are routinely studied in the setting of ischemic heart disease. Abnormal levels of cardiac troponins have also been reported to be associated with poor clinical outcome in patients with acute cerebrovascular diseases, including ischemic stroke (Di Angelantonio et al., 2005; Scheitz et al., 2012; Provide^ncia, Barra \& Paiva, 2013; Faiz et al., 2014), intracerebral hemorrhage (Hays \& Diringer, 2006), and spontaneous subarachnoid hemorrhage (Deibert et al., 2003). Common risk factors for vascular diseases, such as hypertension, diabetes, heart disease, and hyperlipidemia, are well known comorbidities of stroke. Most previous studies emphasized the correlation of these comorbidities with stroke and clinical outcomes. However, the definition of each risk factor is usually not identical and the duration of these risk factors is not well described. The impact of a poorly controlled risk factor on the severity and outcome of stroke is not the same as that of a well-controlled one. Available laboratory parameters and clinical features as well as biomarkers during acute stroke provide valuable information when investigating the clinical outcomes after stroke. In this study, we investigated whether certain clinical features and laboratory parameters including troponin I (TnI) that are commonly measured on admission to the emergency department are predictive of outcome in patients with 
84 acute stroke.

85

86

87

88

89

90

91

92

93

94

95

96

97

98

99

100

101

102

103

104

105

106

Peer] reviewing PDF | (2015:11:7634:2:0:NEW 8 Mar 2016) 
107 Materials \& Methods

108 Study Population and Data Collection

109 Patients who were treated for stroke in the neurological ward from August 2010 to March

1102015 were retrospectively selected from the stroke registry database. Inclusion criteria included a

111 diagnosis of acute ischemic stroke that was confirmed by clinical presentation and proof of an

112 ischemic lesion and/or absence of a corresponding intracranial lesion other than infarction by

113 brain computed tomography or magnetic resonance study, and an available serum TnI study

114 conducted in the emergency department within 48 hours of symptom onset. TnI is considered as

115 a routine study for patients with acute stroke by some but not all emergency physicians. Thus,

116 measurement of TnI became a partial randomization study in the emergency department. Data

117 integrated for analysis in this study included the sex and age of the patients, clinical data such as

118 blood pressure and heart rate, and hematological parameters including the white blood cell count,

119 hemoglobin, hematocrit, blood urea nitrogen, creatinine and TnI levels on arrival in the

120 emergency department, and the severity of stroke evaluated on admission.

121

122 Definitions

123 TnI was measured using a conventional VIDAS Troponin I Ultra assay (bioMerieux, Marcy

124 L'Etoile, France) in the hospital's central laboratory. The analytical limit of detection and the

125 99th percentile upper reference limit was $0.01 \mu \mathrm{g} / \mathrm{L}$. Abnormal elevation of TnI was defined as a

126 TnI blood level $>0.01 \mu \mathrm{g} / \mathrm{L}$. Patients were stratified into two groups according to the TnI level,

127 the normal group $(\leqq 0.01 \mu \mathrm{g} / \mathrm{L})$ and the abnormal group $(>0.01 \mu \mathrm{g} / \mathrm{L})$. Patients with abnormal

128 TnI levels were further stratified into two relatively equal-sized groups, the low-positive group

$129(0.02-0.1 \mu \mathrm{g} / \mathrm{L})$ and the high-positive group $(>0.1 \mu \mathrm{g} / \mathrm{L})($ Scheitz et al., 2014). Stroke severity was 
130 assessed on admission according to the National Institutes of Health Stroke Scale (NIHSS). The

131 etiology of stroke was classified according to the Trial of ORG 10172 in Acute Stroke Treatment

132 (TOAST) criteria (Adams et al., 1993). Clinical deterioration was defined in patients who

133 demonstrated an increase of two or more points in the NIHSS score during the acute stage of

134 stroke (Siegler et al., 2013; Umemura et al., 2014). Outcomes were evaluated using the NIHSS,

135 the Barthel index and the modified Rankin Scale (mRS) at discharge. An mRS score $>2$ was

136 considered to indicate a poor outcome. All causes of death during hospitalization were registered

137 as in-hospital mortality.

138

139 Statistical Analysis

140 Continuous variables are presented as median with interquartile range (IQR) or mean \pm

141 standard deviation. TnI values and mRS scores were analyzed as continuous and dichotomous

142 variables. The chi-square test and Fisher's exact test were used for categorical comparisons of

143 data. Group comparisons of continuous variables were performed using Mann-Whitney U and

144 Kruskal-Wallis H tests for independent samples. Significant predictors in the univariate analyses

145 were transferred to dichotomous variables with the cut-off level according to the mean values of

146 poor outcome, and were subsequently included in a multiple logistic-regression model to identify

147 the most important factors associated with poor outcome, and in a stepwise logistic-regression

148 model with in-hospital death. The predictive performance of the variables including TnI was

149 compared using $c$-statistics. We compared basic models for poor outcome and in-hospital

150 mortality including clinical variables to models that also included information on TnI levels.

151 Comparisons of $c$-statistics were done according to the method of DeLong (DeLong et al. 1988).

152 A $p$ value of less than 0.05 was considered to indicate statistical significance. All statistical 
153 analyses were performed with the statistical package SPSS (Version 17, SPSS Inc, Chicago, IL).

154 The ROC curve comparisons were calculated using R software (version 2.15.3, pROC package).

155 This study was approved by the Institutional Review Board of the Taipei Tzu Chi Hospital 04-

156 XD40-107.

157

158

159

160

161

162

163

164

165

166

167

168

169

170

171

172

173

174

175 
176

177

178

179

180

181

182

183

184

185

186

187

188

189

190

191

192

193

194

195

196

197

198

\section{Results}

During the study period, a total of 2,307 patients presented to our emergency department with acute ischemic stroke. Only 871 of those patients had valid data on TnI levels because during that period, measurement of TnI level was not routinely performed in the emergency department for patients with acute stroke. The average age of the 871 patients with valid TnI data was about 1.2 years older than that of all 2,307 patients $(72.3 \pm 13.6$ vs $71.1 \pm 13.4$ years, $p=$ 0.02, Mann-Whitney test). Other baseline characteristics of the 871 patients with valid TnI data, including male-to-female ratio (1.13 vs 1.21$)$, percentage of patients with cardioembolism (15\% vs $13 \%$ ), average blood pressure, heart rate, laboratory data, and NIHSS on admission (8.3 vs 7.8), did not differ from those of the total 2,307 patients. The median age of the 871 patients enrolled in the study was 74.5 years (IQR $62.7-82.8$ ) and $46.8 \%$ of them were women. The women were significantly older and had lower diastolic blood pressure, hemoglobin levels and hematocrit levels $(p<0.001)$ than the men. The women had higher NIHSS $(p=0.024)$ and mRS scores as well as lower Barthel index scores at discharge, and poorer outcomes $(p<0.001)$ than the men. The mortality rate was significantly higher in the men $(p=0.017)$. Elevated TnI levels were observed in 146 of the 871 patients (16.8\%). Of these, $77(8.8 \%)$ had high-positive levels and $69(7.9 \%)$ had low-positive levels. Table 1 shows the comparison of clinical features, laboratory data, severity of stroke, and outcomes of patients with different levels of TnI. Abnormal TnI levels were more common in patients with stroke due to large artery atherosclerosis $(54 / 232=23 \%)$, cardioembolism $(38 / 131=29 \%)$, and undetermined etiology $(5 / 17=29 \%)$ than in patients with stroke due to small vessel occlusion $(48 / 482=10 \%)$ and other determined etiology $(1 / 9=11 \%)$ according to the TOAST classification. Patients with abnormal TnI levels were significantly older $(p<0.001)$ than patients with normal TnI levels and had 
199 significantly higher heart rates $(p=0.018)$, white blood cell counts $(p=0.025)$, and creatinine

200 levels $(p<0.001)$ and significantly lower hemoglobin $(p=0.006)$ and hematocrit levels $(p=$

201 0.025). In addition, patients with abnormal TnI levels had higher median NIHSS scores on

202 admission (11, IQR 5-21) and at discharge (8, IQR 4-22) than patients with normal TnI levels (4,

203 IQR 2-9 and 3, IQR 1-4, respectively) $(p<0.001)$. The median Barthel index was lower (20, IQR

204 0-75) and the mRS was higher (4, IQR 3-5) in patients with abnormal $\mathrm{TnI}$ than in patients with

205 normal TnI (75, IQR 35-100 and 3, IQR 1-4, respectively) $(p<0.001)$. Poor outcomes were

206 observed in $509(58 \%)$ of the 871 patients and death occurred in $31(3.6 \%)$ patients. Patients with

207 abnormal TnI levels had longer hospital stays (16 days vs 9 days), higher rates of clinical

208 deterioration $(18 \%$ vs $9 \%, p=0.005)$, poor outcome $(79 \%$ vs $54 \%, p<0.001)$, and death $(14 \%$

209 vs $2 \%, p<0.001)$ than patients with normal TnI levels. All the differences were more prominent

210 in the high-positive group. There were mor poor outcomes $(85 \%)$ and deaths $(21 \%)$ in the high-

211 positive group than in the low-positive group (74\% and 6\%, respectively).

212 Univariate analyses of continuous variables revealed that patients with poor outcomes were

213 older, and had higher heart rates, TnI levels, white blood cell counts, creatinine levels, and

214 NIHSS scores on admission and at discharge, and higher mRS scores at discharge but lower

215 hemoglobin levels, hematocrit levels, and Barthel index scores than those with better outcomes

216 (Table 2). Analysis of dichotomous variables revealed that female gender, cardioembolism,

217 abnormal TnI levels, and evidence of clinical deterioration were associated with poor outcomes.

218 In-hospital death was associated with high systolic blood pressure, high heart rate, high TnI level,

219 high white blood cell count, and high NIHSS score on admission, and longer length of stay.

220 Dichotomous analysis showed significant correlation of male gender, abnormal TnI levels, and

221 evidence of clinical deterioration with in-hospital death. Age was not associated with in-hospital 
222 death.

223 Table 3 showed the regression analysis of the significant dichotomous variables with the

224 cut-off levels according to the mean values of poor outcome in Table 2. Multivariate logistic

225 regression analysis revealed that age $\geqq 76$ years $(p<0.001)$, heart rate $\geqq 83 \mathrm{bpm}(p=0.001)$,

226 evidence of clinical deterioration $(p<0.001)$, NIHSS score $\geqq 14$ on admission $(p<0.001)$, and

227 abnormal TnI level (odds ratio [OR]: 1.98; 95\% confidence interval [CI]: 1.18-3.33; $p=0.01$ )

228 were significant predictors of poor outcome. A stepwise backward regression analysis showed

229 male gender $(p=0.006)$, evidence of clinical deterioration $(p<0.001)$, NIHSS score $\geqq 12$ on

230 admission $(p<0.001)$, and abnormal TnI level (OR: 5.59; 95\% CI: 2.36-13.27; $p<0.001)$ were

231 significant predictors of in-hospital mortality.

$232 C$-statistics of regression models for detection of poor outcome and death for each factor are

233 shown in Table 4. $C$-statistics for detection of poor outcome was 0.691 for NIHSS score $\geqq 12$ on

234 admission. The addition of age $\geqq 76$ years, evidence of clinical deterioration, and $\mathrm{TnI} \geqq 0.01$

$235 \mathrm{ug} / \mathrm{L}$ to the regression model resulted in significant improvement of the $c$-statistics to $0.787(p<$

236 0.05). The addition of $\mathrm{TnI}>0.01 \mathrm{ug} / \mathrm{L}$ or $\mathrm{TnI}>0.1 \mathrm{ug} / \mathrm{L}$ to a model-fitting including significant

237 factors in logistic regression (NIHSS score on admission $\geqq 12$, age $\geqq 76$ years, evidence of

238 clinical deterioration, heart rate $\geqq 82 \mathrm{bpm}$ ) did not improve the predictive value foro poor

239 outcome. Similar results were observed for detection of death. $C$-statistics for detection of death

240 was 0.790 for an NIHSS score $\geqq 12$ on admission. The addition of $\mathrm{TnI} \geqq 0.01 \mathrm{ug} / \mathrm{L}$ and

241 evidence of clinical deterioration to the regression model resulted in significant improvement of

242 the $c$-statistics to $0.912(p<0.05)$. The addition of $\mathrm{TnI}>0.01 \mathrm{ug} / \mathrm{L}$ or $\mathrm{TnI}>0.1 \mathrm{ug} / \mathrm{L}$ to a model-

243 fitting including NIHSS $\geqq 12$ on admission, evidence of deterioration and male gender

244 significantly improved the predictive value for death from 0.887 to 0.926 and 0.927 , respectively 
$245(p<0.05)$.

246

247

248

249

250

251

252

253

254

255

256

257

258

259

260

261

262

263

264

265

266

267 


\section{Discussion}

269 TnI is a highly sensitive and specific marker of acute myocardial infarction. Elevated TnI is

270 characteristic of a number of cardiac diseases as well such as heart failure, pericarditis,

271 myocarditis, atrial fibrillation and tachycardia (Tanindi \& Cemri, 2011). Elevated TnI has also

272 been found in patients with chronic renal failure, sepsis, critical illness, pulmonary embolism,

273 chronic obstructive pulmonary disease, and stroke (Tanindi \& Cemri, 2011; Mannu, 2014).

274 Elevated levels of cardiac troponin have been reported in 10-34\% of patients with acute stroke.

275 Kerr et al conducted a systematic review of studies measuring troponin within 7 days of

276 symptom onset in acute stroke patients and found that more than $18 \%$ of patients had a high

277 troponin level (Kerr et al., 2009). Some studies reported that elevated troponin levels were more

278 common in patients with stroke due to cardioembolism who also had evidence of atrial

279 fibrillation, ischemic heart or heart failure (Etgen et al., 2005; Faiz et al., 2014). Abnormal TnI

280 levels were observed in $16.8 \%$ patients in our study. We found that patients with abnormal TnI

281 were more likely to have large artery atherosclerosis, cardioembolism and undetermined etiology.

282 Patients who had risks from both atrial fibrillation and stenotic cerebral arteries were grouped

283 into undetermined etiology with conflicting data when categorizing the subtype of stroke. This

284 could explain why there was a similarly higher percentage of elevated TnI levels in patients with

285 undetermined etiology. Patients with elevated TnI levels were older and had higher heart rates

286 and creatinine levels but lower hemoglobin levels and hematocrits than patients with normal TnI

287 levels. Patients with elevated TnI presented with more severe initial stroke severity and showed a

288 greater degree of clinical deterioration during hospitalization. Worse outcomes and higher in-

289 hospital mortality were observed in patients with abnormal TnI as well. All of the above

290 differences were most prominent in patients with high-positive TnI levels. These findings are 
291 similar to those reported by Di Angelantonio et al, who found a dose-response relationship

292 between the three TnI groups (normal, low-positive, and high-positive) and clinical features (Di

293 Angelantonio et al., 2005).

294 Mechanisms for elevated TnI during acute ischemic stroke may be separated into 2 major 295 groups, (1) ischemic myocardial injury (ie, because of coronary ischemia) and (2) nonischemic 296 (noncoronary) myocardial injury (Scheitz et al. 2015a). Coronary plaque rupture or mismatch

297 between oxygen demand and supply (such as in tachyarrhythmia, hypertensive crisis, or 298 respiratory failure) may cause ischemic myocardial injury. Nonischemic myocardial injury 299 comprises neurogenic heart syndrome and noneurogenic conditions (severe infection or sepsis,

300 heart or renal failure, pulmonary embolism). In neurogenic heart syndrome, acute stroke-related 301 increased sympathetic activity with excessive catecholamine release results in coagulative

302 myocytolysis (also known as contraction band necrosis or myofibrillar degeneration) or 303 cardiomyopathy. Myocytolysis surrounding patches of subendocardial hemorrhage or swollen

304 myocytes surrounding epicardiac nerves during early acute stroke has been suggested to be the 305 cause of cardiac injury (Oppenheimer \& Hachinski, 1992). Barber et al found that raised TnI was 306 associated with elevation of circulating epinephrine in patients with acute ischemic stroke

307 (Barber et al., 2007). Involvement of the parietal lobe or insular cortex has also been associated 308 with elevated cardiac troponin levels due to the imbalance of sympathetic and parasympathetic 309 autonomic control (Ay et al., 2006; Rincon et al., 2008; Scheitz et al., 2015b). Not all patients in 310 our study underwent brain magnetic resonance imaging to indentify the precise location of the 311 stroke; therefore, we were not able to analyze the involvement of the insular or parietal cortex.

312 Cardiac cell damage with elevated troponins in acute stroke may be enhanced by the stress313 related inflammatory response as well as the cytokine response pathways (Christensen et al., 
314 2004). The etiologies of elevated troponin levels other than acute coronary syndrome in renal

315 failure include subclinical myocardial damage (micro-infarctions) and decreased renal troponin

316 excretion (Freda et al., 2002; Jensen et al., 2007; Faiz et al., 2014). Serum troponin T is increased

317 more frequently than $\mathrm{TnI}$ in patients with renal failure, and $\mathrm{TnI}$ has been reported to be a more

318 sensitive and specific biomarker of cardiac damage than Troponin $\mathrm{T}$ in patients with end-stage

319 renal failure (Freda et al., 2002; Mannu, 2014).

320 There is no doubt that advanced age, higher NIHSS score on admission, and evidence of

321 clinical deterioration during hospitalization are associated with a worse outcome and higher

322 death rate at discharge. The average age of patients with abnormal TnI, patients with poor

323 outcome, and patients who died in the hospital in this study was approximately 76 years. Faiz et

324 al also reported that age $\geqq 76$ years was independently associated with elevated troponin levels

325 in patients with acute ischemic stroke (Faiz et al., 2014). A high heart rate was associated with

326 worse outcomes, in particular death, in a long-term follow-up study of patients with vascular

327 diseases (Erdur et al., 2014). In our study, a higher heart rate was observed in patients with

328 abnormal TnI (83 bpm), in those with poor outcome (82 bpm), and in those who died before

329 discharge $(87 \mathrm{bpm})$ than those without these factors. Multivariate analysis revealed that heart rate

$330 \geqq 82 \mathrm{bpm}$ was also an independent risk factor for poor outcome. Erdur et al reported that heart

331 rate $\geqq 83 \mathrm{bpm}$ on admission was independently associated with in-hospital mortality in acute

332 ischemic stroke patients, suggesting early negative effects of autonomic imbalance (Erdur et al., 333 2014).

334 With the exception of the NIHSS score on admission and subsequent deterioration during

335 hospitalization, only elevated TnI was a strong independent predictor of both poor outcome and 336 death. Abnormal TnI had an OR of 1.98 for poor outcome and an OR of 5.59 for in-hospital 
337 mortality. A meta-analysis of 2901 patients from 15 studies with different definitions and

338 sampling times for troponin by Kerr et al revealed that elevated troponin is associated with poor

339 outcome; however, they did not fully establish whether elevated troponin is an independent

340 prognostic factor (Kerr et al., 2009). Recent studies with multivariate models including age and

341 some measures of stoke severity have concluded that a positive level of troponin is associated

342 with an overall increased risk of both death and disability (Jensen et al., 2007; Faiz et al., 2014a;

343 Faiz et al., 2014b). In the present study, $c$-statistics revealed that abnormal TnI improved the

344 predictive power of both poor outcome and in-hospital mortality. Although the predictive

345 performance of abnormal TnI for poor outcome was relative low in a categorized model with

346 strong predictors, such as NIHSS score $\geqq 12$ on admission and evidence of deterioration, both

347 low-positive and high-positive TnI significantly increased the discriminative power of the model

348 for in-hospital death. The American Stroke Association recommends the routine checking of

349 markers of cardiac ischemia during acute stroke (Adams et al., 2007). Whether troponin should

350 be routinely checked is still under deliberation. Nevertheless, recognition and careful

351 investigation of possible concomitant cardiac disorders in patients with acute ischemic stroke is

352 warranted for patients with elevated troponin levels.

353 The newly developed high-sensitivity assay of troponin allows for precise detection of

354 troponin even at concentrations 10-fold lower than conventional assays (Wu \& Jaffe, 2008). A

355 high-sensitivity troponin test improves the diagnosis of patients with acute myocardial infarct.

356 However, reduction of specificity comes with improvement in sensitivity. In Scheitz's series,

357 troponin T elevation above the 99th percentile was detected with a high-sensitivity assay in more 
358 than $50 \%$ of patients with acute ischemic stroke, and even moderately elevated troponin $\mathrm{T}$ was

359 associated with an unfavorable outcome (Scheitz et al,. 2014). The presence of high positive or

360 dynamic change troponin levels might indicate ischemic myocardial injury. Stroke patients with

361 dynamic changes in troponin levels $(>50 \%)$ within 24 hours showed a higher risk for in-hospital

362 mortality than patients with increased troponin levels who were stable over time (Scheitz et al.,

363 2014). Serial measurements should be performed to establish whether troponin is acutely or

364 chronically elevated. For patients with non-acute elevation of troponin levels, out-patients

365 evaluation for structural or coronary heart disease is recommended. For patients with high

366 positive or a dynamic pattern of elevated troponin levels, prompt measures for prevention of

367 cardiovascular disease should be intensified or reevaluated. Noninvasive echocardiography,

368 cardiac magnetic resonance imaging or computed tomography may help to identify possible

369 unstable coronary disease, heart failure, or cardiomyopathy. Invasive coronary angiography may

370 be indicated for patients with acute myocardial infarction (Scheitz et al. 2015a).

371 This study has a number of limitations. First, this study was retrospective in nature. There

372 was selection bias exits because of only a small group of patents received TnI measurement.

373 Second, TnI was checked only once in each patient in the emergency room without an exact time

374 period of onset-of-symptoms to troponin measurement. Dynamic change measurement of TnI

375 might provide more prognostic relevance in acute ischemic stroke. Third, the low number of

376 patients with the outcome "death" might limit meaningfulness although stepwise logistic 
377 regression analysis was used. Finally, we did not perform a follow-up study after discharge.

378 Notwithstanding these limitations, our data extend the current understanding of the implications

379 of troponin positivity in acute ischemic stroke.

380

381

382

383

384

385

386

387

388

389

390

391

392

393

394

395

396

397

398

399 


\section{Conclusions}

401 Troponin I provide better information than age and other laboratory parameters in

402 prediction of outcome of stroke, even after adjustment for the strong impact factors of stroke

403 severity and presence of clinical deterioration. Elevation of TnI during acute stroke is a strong

404 independent predictor of both poor outcome and in-hospital mortality. Both neurologists and

405 cardiologists need to pay more attention to possible concomitant cardiac disorders in patients

406 with abnormal troponin levels during acute stroke.

407

408

409

410

411

412

413

414

415

416

417 


\section{References}

419 Adams HP Jr, Bendixen BH, Kappelle LJ, Biller J, Love BB, Gordon DL, Marsh EE 3rd. 1993.

420 Classification of subtype of acute ischemic stroke. Definitions for use in a multicenter clinical

421 trial. Stroke 24:35-41. DOI: 10.1161/01.STR.24.1.35.

422 Adams HP Jr, del Zoppo G, Alberts MJ, Bhatt DL, Brass L, Furlan A, Grubb RL, Higashida

423 RT, Jauch EC, Kidwell C, Lyden PD, Morgenstern LB, Qureshi AI, Rosenwasser RH, Scott

424 PA, Wijdicks EF; American Heart Association; American Stroke Association Stroke Council;

425 Clinical Cardiology Council; Cardiovascular Radiology and Intervention Council;

426 Atherosclerotic Peripheral Vascular Disease and Quality of Care Outcomes in Reasearch

427 Interdisciplinary Working Groups. 2007. Guidelines for the early management of adults with

428 ischemic stroke: a guideline from the American Heart Association/ American Stroke

429 Association Stroke Council, Clinical Cardiology Council, Cardiovascular Radiology and

430 Intervention Council, and the Atherosclerotic Peripheral Vascular Disease and Quality of Care

431 Outcomes in Research Interdisciplinary Working Groups: the American Academy of

432 Neurology affirms the value of this guideline as an educational tool for neurologists. Stroke 38:

433

1655-1711. DOI: 10.1161/STROKEAHA.107.181486.

434 Adams RJ, Chimowitz MI, Alpert JS, Awad IA, Cerqueria MD, Fayad P, Taubert KA. 2003.

435 Coronary risk evaluation in patients with transient ischemic attack and ischemic stroke: a 
436 scientific statement for healthcare professionals from the Stroke Council and the Council on

437 Clinical Cardiology of the American Heart Association/American Stroke Association. 34:2310

$438 \quad$-2322. DOI: 10.1161/01.STR0000090125.28466.E2

439 Ay H, Koroshetz WJ, Benner T, Vangel MG, Melinosky C, Arsava EM, Ayata C, Zhu

440 M, Schwamm LH, Sorensen AG. 2006. Neuroanatomic correlates of stroke-related myocardial

441 injury. Neurology 66:1325-1329. DOI: 10.1212/01.wnl.0000206077.13705.6d.

442 Barber M, Morton JJ, Macfarlane PW, Barlow N, Roditi G, Stott DJ. 2007. Elevated troponin

443 levels are associated with sympathoadrenal activation in acute ischaemic stroke. Cerebrovasc

444 Dis 23:260-266. DOI:10.1159/000098325.

445 Bounds JV, Wiebers DO, Whisnant JP, Okazaki H. 1981. Mechanisms and timing of deaths from

446 cerebral infarction. Stroke 12:474-477. DOI: 10.1161/01.STR.12.4.474.

447 Christensen H, Johannesen HH, Christensen AF, Bendtzen K, Boysen G. 2004. Serum cardiac

448 troponin I in acute stroke is related to serum cortisol and TNF- $\alpha$. Cerebrovasc Dis 18: 194-199.

449 DOI:10.1159/000079941.

450 Deibert E, Barzilai B, Braverman AC, Edwards DF, Aiyagari V, Dacey R, Diringer M. 2003.

451 Clinical significance of elevated troponin I in patients with nontraumatic subarachnoid

452 hemorrhage. J Neurosurg 98:741-746. DOI: 10.3171/jns.2003.98.4.0741.

453 DeLong ER, DeLong DM, Clarke-Pearson DL. 1988. Comparing the areas under two or more 
454 correlated receiver operating characteristic curves: a nonparametric approach.

455 Biometrics 44(3): 837-45. DOI: $10.2307 / 2531595$

456 Di Angelantonio E, Fiorelli M, Toni D, Sacchetti ML, Lorenzano S, Falcou A, Ciarla MV, Suppa

457 M, Bonanni L, Bertazzoni G,Aguglia F, Argentino C. 2005. Prognostic significance of

458 admission levels of troponin I in patients with acute ischaemic stroke. J Neurol Neurosurg

459 Psychiatry 76:76-81. DOI: 10.1136/jnnp.2004.041491.

460 Erdur H, Scheitz JF, Grittner U, Laufs U, Endres M, Nolte CH. 2014. Heart rate on admission

461 independently predicts in-hospital mortality in acute ischemic stroke patients. Int J Cardiol

462 176:206-210. DOI: 10.1016/j.ijcard.2014.07.001.

463 Etgen T, Baum H, Sander K, Sander D. 2005. Cardiac Troponins and N-terminal Pro-brain

464 natriuretic peptide in acute ischemic stroke do not relate to clinical prognosis. Stroke 36: 270-

465 275. DOI: 10.1161/01.STR.0000151364.19066.a1.

466 Faiz KW, Thommessen B, Einvik G, Brekke PH, Omland T, Rønning OM. 2014. Determinants

467 of high sensitivity cardiac troponin T elevation in acute ischemic stroke. BMC Neurol 14:96.

468 DOI: $10.1186 / 1471-2377-14-96$.

469 Faiz KW, Thommessen B, Einvik G, Omland T, Rønning OM. 2014. Prognostic value of high-

470 sensitivity cardiac Troponin T in acute ischemic stroke. J Stroke Cerebrovasc Dis 23: 241-248.

471 DOI: 10.1016/j.jstrokecerebrovasdis.2013.01.005. 
472 Freda BJ, Tang WH, van Lente F, Peacock WF, Francis GS. 2002. Cardiac troponins in renal

473 insufficiency: review and clinical implications. J Am Coll Cardiol 40:2065-2071. DOI:

$474 \quad 10.1016 / \mathrm{S} 0735-1097(02) 02608-6$.

475 Hays A, Diringer MN. 2006. Elevated troponin levels are associated with higher mortality

476 following intracerebral hemorrhage. Neurology 66:1330-1334. DOI: 10.1212/01.wnl.

$477 \quad 0000210523.22944 .9 b$.

478 Jensen JK, Kristensen SR, Bak S, Atar D, Høilund-Carlsen PF, Mickley H. 2007. Frequency and

479 significance of troponin T elevation in acute ischemic stroke. Am J Cardiol 99:108-112. DOI:

$480 \quad$ 10.1016/j.amjcard.2006.07.071.

481 Kerr G, Ray G, Wu O, Stott DJ, Langhorne P. 2009. Elevated troponin after stroke: a systematic

482 review. Cerebrovasc Dis 28:220-226. DOI: 10.1159/000226773.

483 Mannu GS. 2014. The non-cardiac use and significance of cardiac troponins. Scot Med J 59:

484 172-178. DOI: $10.1177 / 0036933014540090$.

485 Oppenheimer SM, Hachinski VC. 1992. The cardiac consequences of stroke. Neurol Clin 10:

$486 \quad 167-176$.

487 Prosser J, MacGregor L, Lees KR, Diener HC, Hacke W, Davis S; VISTA Investigators. 2007

488 Predictors of early cardiac morbidity and mortality after ischemic stroke. Stroke 38:2295-2302.

489 DOI: $10.1161 /$ STROKEAHA. 106.471813 
490 Provide^ncia R, Barra S, Paiva L. 2013. Atrial fibrillation, elevated troponin, ischemic stroke and

491 adverse outcomes: understanding the connection. Clin Res Cardiol 102:701-711. DOI:

$492 \quad 10.1007 / \mathrm{s} 00392-013-0591-0$.

493 Rincon F, Dhamoon M, Moon Y, Paik MC, Boden-Albala B, Homma S, Di Tullio MR, Sacco

494 RL, Elkind MS. 2008. Stroke location and association with fatal cardiac outcomes: Northern

495 Manhattan Study (NOMAS). Stroke 39:2425-2431. DOI: 10.1161/STROKEAHA.107.50605 5.

496 Scheitz JF, Endres M, Mochmann HC, Audebert HJ, Nolte CH. 2012. Frequency, determinants

497 and outcome of elevated troponin in acute ischemic stroke patients. Int J Cardiol 157:239-242.

498 DOI: 10.1016/j.ijcard.2012.01.055.

499 Scheitz JF, Mochmann H-C, Erdu H, Tütüncü S, Haeusler KG, Grittner U, Laufs U, Endres M,

500 Nolte CH. 2014. Prognostic relevance of cardiac troponin T levels and their dynamic changes

501 measured with a high-sensitivity assay in acute ischaemic stroke: analyses from the TRELAS

502 cohort. Int J Cardiol. 177:886-893. DOI: 10.1016/j.ijcard.2014.10.036.

503 Scheitz JF, Nolte CH, Laufs U, Endres M. 2015a. Application and interpretation of high-

504 sensitivity cardiac troponin assays in patients with acute ischemic stroke. Stroke. 46:1132-1140.

505 DOI: 10.1161/STROKEAHA.114.007858.

506 Scheitz JF, Erdur H, Haeusler KG, Audebert HJ, Roser M, Laufs U, Endres M, Nolte CH. 2015 b.

507 Insular cortex lesions, cardiac troponin, and detection of previously unknown atrial fibrillation 
508 in acute ischemic stroke: insights from the troponin elevation in acute ischemic stroke study.

$509 \quad$ Stroke 46:1196-201. DOI: 10.1161/STROKEAHA.115.008681.

510 Siegler JE, Boehme AK, Kumar AD, Gillette MA, Albright KC, Martin-Schild S. 2013. What

511 change in the National Institutes of Health Stroke Scale should define neurologic deterioration

512 in acute ischemic stroke? J Stroke Cerebrovas Dis 22(5): 675-682. DOI:

$513 \quad$ 10.1016/j.jstrokecerebrovasdis.2012.04.012

514 Tanindi A, Cemri M. 2011. Troponin elevation in conditions other than acute coronary

515 syndromes. Vasc Health Risk Manag 7:597-603. DOI: 10.2147/VHRM.S24509.

516 Umemura T, Senda J, Fukami Y, Mashita S, Kawamura T, Sakakibara T, Sobue G. 2014. Impact

517 of albuminuria on early neurological deterioration and lesion volume expansion in

518 lenticulostriate small infarcts. Stroke 45:587-590. DOI: 10.1161/STROKEAHA.113.003164/-

$519 \quad / \mathrm{DC} 1$.

$520 \mathrm{Wu}$ AH, Jaffe AS. 2008. The clinical need for high-sensitivity cardiac troponin assays for acute

521 coronary syndromes and the role for serial testing. Am Heart J. 155:208-214. DOI:

$522 \quad$ 10.1016/j.ahj.2007.10.016. 
Table 1. Correlation of clinical features and troponin I level in 871 patients with acute ischemic stroke

\begin{tabular}{|c|c|c|c|c|c|c|c|}
\hline \multirow[b]{2}{*}{ Characteristics } & \multicolumn{3}{|c|}{ Troponin I test a } & \multicolumn{4}{|c|}{ Troponin I level (ug/L) ${ }^{b}$} \\
\hline & $\begin{array}{l}\text { Abnormal }(>0.01 \mathrm{ug} / \mathrm{L}) \\
\qquad(\mathrm{n}=146)\end{array}$ & $\begin{array}{l}\text { Normal } \\
(\mathrm{n}=725)\end{array}$ & $P$ value & $\begin{array}{c}>0.1 \\
(\mathrm{n}=77)\end{array}$ & $\begin{array}{l}0.02-0.1 \\
(\mathrm{n}=69)\end{array}$ & $\begin{array}{c}\leqq 0.01 \\
(\mathrm{n}=725)\end{array}$ & $P$ value \\
\hline Median age (years) & $77.6(66.2-85.6)$ & $73.8(61.6-82.2)$ & $<0.001$ & $77.7(67.2-84.9)$ & $77.5(65.4-85.9)$ & $73.8(61.6-82.2)$ & 0.003 \\
\hline Systolic pressure (mmHg) & $160(144-192)$ & $162(144-184)$ & 0.972 & $157(140-188)$ & $164(145-195)$ & $162(144-184)$ & 0.615 \\
\hline Diastolic pressure (mmHg) & $87(76-103)$ & $90(79-101)$ & 0.294 & $87(74-102)$ & $87(76-106)$ & $90(79-101)$ & 0.567 \\
\hline Heart rate (bpm) & $80(73-90)$ & $78(67-89)$ & 0.015 & $84(71-94)$ & $80(74-88)$ & $78(67-89)$ & 0.029 \\
\hline White blood cells $\left(1000 / \mathrm{mm}^{3}\right)$ & $8.40(6.48-7.03)$ & $7.50(6.11-9.53)$ & 0.025 & $9.10(7.11-11.01)$ & $7.44(5.81-9.14)$ & $7.50(6.11-9.53)$ & $<0.001$ \\
\hline Hemoglobin $(\mathrm{g} / \mathrm{dL})$ & $13.0(11.1-14.8)$ & $13.7(12.3-14.9)$ & 0.006 & $12.9(10.9-15.2)$ & $13.1(11.2-14.6)$ & $13.7(12.3-14.9)$ & 0.021 \\
\hline Hematocrite (\%) & $39.0(34.0-43.2)$ & $40.0(36.0-43.0)$ & 0.025 & $38.0(33.8-44.0)$ & $39.0(34.0-43.0)$ & $40.0(36.0-43.0)$ & 0.074 \\
\hline Glucose (mg/dL) & $144(115-118)$ & $139(112-185)$ & 0.612 & $156(123-213)$ & $133(113-158)$ & $139(112-185)$ & 0.065 \\
\hline Creatinine (mg/dL) & $1.40(1.00-2.20)$ & $1.10(0.90-1.30)$ & $<0.001$ & $1.40(1.00-2.40)$ & $1.30(1.0-2.0)$ & $1.10(0.90-1.30)$ & $<0.001$ \\
\hline NIHSS score (on admission) & $11(5-21)$ & $4(2-9)$ & $<0.001$ & $11(6-23)$ & $10(4-20)$ & $4.0(2-9)$ & $<0.001$ \\
\hline NIHSS score (at discharge) & $8(4-22)$ & $3(1-7)$ & $<0.001$ & $11(4-32)$ & $6(3-15)$ & $3(1-7)$ & $<0.001$ \\
\hline Barthel index score & $20(0-75)$ & $75(35-100)$ & $<0.001$ & $18(0-66)$ & $30(5-85)$ & $75(35-100)$ & $<0.001$ \\
\hline modified Rankin Scale & $4(3-5)$ & $3(1-4)$ & $<0.001$ & $5(4-5)$ & $4(1-5)$ & $3(1-4)$ & $<0.001$ \\
\hline Length of stay (days) & $16(8-29)$ & $9(5-24)$ & $<0.001$ & $19(9-29)$ & $14(6-28)$ & $9(5-24)$ & $<0.001$ \\
\hline Deterioration $^{\mathrm{c}}$ & $26(18 \%)$ & $68(9 \%)$ & 0.005 & $16(21 \%)$ & $10(15 \%)$ & $68(9 \%)$ & 0.006 \\
\hline $\mathrm{mRS}>2^{\mathrm{c}}$ & $116(79 \%)$ & $393(54 \%)$ & $<0.001$ & $65(85 \%)$ & $50(74 \%)$ & $393(54 \%)$ & $<0.001$ \\
\hline Death $^{c}$ & $20(14 \%)$ & $11(2 \%)$ & $<0.001$ & $16(21 \%)$ & $4(6 \%)$ & $11(2 \%)$ & $<0.001$ \\
\hline
\end{tabular}

524 Notes.

525 NIHSS, National Institute of health Stroke Scale; mRS, modified Rankin Scale; a, Mann-Whitney U test; b, Kruskal-Wallis test; c, Chi-square test.

526 Data are expressed as median (IQR) or $\mathrm{n}(\%)$ 
529 Table 2. Correlation of clinical features and outcomes in 871 patients with acute ischemic stroke

\begin{tabular}{|c|c|c|c|c|c|c|c|c|}
\hline \multirow[b]{2}{*}{ Characteristics } & \multicolumn{5}{|c|}{ Poor outcome $(\mathrm{mRS}>2)^{\mathrm{a}}$} & \multicolumn{3}{|c|}{ Death $^{\text {a }}$} \\
\hline & $\mathrm{Y}(\mathrm{n}=509)$ & $\mathrm{N}(\mathrm{n}=362)$ & $\mathrm{Y}(\mathrm{n}=509)$ & $\mathrm{N}(\mathrm{n}=362)$ & $\begin{array}{c}P \\
\text { value }\end{array}$ & $Y(n=31)$ & $\mathrm{N}(\mathrm{n}=840)$ & $\begin{array}{c}P \\
\text { value }\end{array}$ \\
\hline Systolic pressure (mmHg) & $165 \pm 32$ & $164 \pm 29$ & $162(144-186)$ & $163(144-184)$ & 0.904 & $182(150-200)$ & $162(144-184)$ & 0.034 \\
\hline Diastolic pressure $(\mathrm{mmHg})$ & $89 \pm 18$ & $92 \pm 18$ & $88(77-102)$ & $91(80-101)$ & 0.114 & $86(72-106)$ & $89(79-101)$ & 0.972 \\
\hline Troponin I (ug/L) & $0.119 \pm 0.656$ & $0.022 \pm 0.101$ & $0.01(0.01-0.01)$ & $0.01(0.01-0.01)$ & $<0.001$ & $0.09(0.01-0.65)$ & $0.01(0.01-0.01)$ & $<0.001$ \\
\hline White blood cells $\left(1000 / \mathrm{mm}^{3}\right)$ & $8.32 \pm 3.03$ & $7.84 \pm 2.65$ & $7.81(6.20-9.98)$ & $7.40(6.19-9.26)$ & 0.039 & $9.00(6.71-11.80)$ & $7.60(6.20-9.61)$ & 0.022 \\
\hline Hemoglobin $(\mathrm{g} / \mathrm{dL})$ & $13.1 \pm 2.2$ & $13.9 \pm 2.0$ & $13.3(11.7-14.5)$ & $14.0(12.7-15.2)$ & $<0.001$ & $13.5(11.3-14.9)$ & $13.6(12.2-14.9)$ & 0.698 \\
\hline Hematocrite (\%) & $38.7 \pm 5.9$ & $40.7 \pm 5.1$ & $39(35-43)$ & $41(38-44)$ & $<0.001$ & $39(35-43)$ & $40(36-43)$ & 0.631 \\
\hline Glucose (mg/dL) & $169 \pm 88$ & $164 \pm 84$ & $144(115-195)$ & $134(109-187)$ & 0.054 & $162(136-205)$ & $139(113-194)$ & 0.130 \\
\hline Barthel index score & $34.5 \pm 28.9$ & $95.7 \pm 9.3$ & $35(5-60)$ & $100(95-100)$ & $<0.001$ & - & - & \\
\hline modified Rankin Scale & $4.2 \pm 0.9$ & $0.9 \pm 0.6$ & $4(4-5)$ & $1(1-1)$ & $<0.001$ & - & - & \\
\hline Length of stay (days) & $23.2 \pm 16.8$ & $6.8 \pm 5.2$ & $20(10-30)$ & $5(4-8)$ & $<0.001$ & $9(3-24)$ & $11(5-25)$ & 0.213 \\
\hline Male gender ${ }^{b}$ & & & $243(48 \%)$ & $220(61 \%)$ & $<0.001$ & $23(74 \%)$ & $440(52 \%)$ & 0.017 \\
\hline Cardioembolism $^{\mathrm{b}}$ & & & $95(19 \%)$ & $36(10 \%)$ & $<0.001$ & $7(23 \%)$ & $124(15 \%)$ & 0.301 \\
\hline Abnormal troponin $\mathrm{I}^{\mathrm{b}}$ & & & $116(23 \%)$ & $30(8 \%)$ & $<0.001$ & $20(65 \%)$ & $126(15 \%)$ & $<0.001$ \\
\hline Deterioration ${ }^{b}$ & & & $86(17 \%)$ & $8(2 \%)$ & $<0.001$ & $18(58 \%)$ & $76(9 \%)$ & $<0.001$ \\
\hline
\end{tabular}


531 mRS, modified Rankin Scale; IQR, interquartile range; NIHSS, National Institute of health Stroke Scale; a, Mann-Whitney U test; b, Chi-square test.

Data are expressed as mean \pm sd, median (IQR) or $\mathrm{n}(\%)$

Table 3. Regression model of factors influencing outcomes and mortality in 871 patients with acute ischemic stroke

\begin{tabular}{|c|c|c|c|c|}
\hline \multirow[b]{2}{*}{ Characteristics } & \multicolumn{2}{|c|}{ Poor outcome $(\mathrm{mRS}>2)^{\mathrm{a}}$} & \multicolumn{2}{|c|}{ Death ${ }^{b}$} \\
\hline & OR $(95 \% \mathrm{CI})$ & $P$ value & OR $(95 \% \mathrm{CI})$ & $P$ value \\
\hline Male gender & $0.75(0.53-1.06)$ & 0.108 & $3.69(1.45-9.44)$ & 0.006 \\
\hline Age $\geqq 76$ years & $2.25(1.59-3.18)$ & $<0.001$ & & \\
\hline Heart rate $\geqq 82 \mathrm{bpm}$ & $1.47(1.05-2.05)$ & 0.026 & & \\
\hline White blood cells $\geqq 8320 \mathrm{uL}$ & $1.21(0.86-1.70)$ & 0.264 & & \\
\hline Hemoglobin $\leqq 13.1 \mathrm{~g} / \mathrm{dL}$ & $1.44(0.78-2.65)$ & 0.245 & & \\
\hline Hematocrite $\leqq 38.7 \%$ & $1.22(0.68-2.23)$ & 0.508 & & \\
\hline Creatinine $\geqq 1.52 \mathrm{mg} / \mathrm{dL}$ & $1.05(0.67-1.64)$ & 0.848 & & \\
\hline Cardioembolism & $0.85(0.50-1.46)$ & 0.573 & & \\
\hline Deterioration & $9.45(4.27-20.94)$ & $<0.001$ & $10.78(4.59-25.33)$ & $<0.001$ \\
\hline NIHSS score (admission) $\geqq 12$ & $19.52(9.59-39.73)$ & $<0.001$ & $8.08(3.04-21.48)$ & $<0.001$ \\
\hline Troponin $\mathrm{I}>0.01 \mathrm{ug} / \mathrm{L}$ & $1.98(1.18-3.33)$ & 0.010 & $5.59(2.36-13.27)$ & $<0.001$ \\
\hline
\end{tabular}

535 Notes.

536 NIHSS, National Institute of Health Stroke Scale; mRS, modified Rankin Scale; OR, odds ratio; CI, confidence

537 interval; ${ }^{\mathrm{a}}$ multiple logistic regression; ${ }^{\mathrm{b}}$ stepwise backward regression. 
543 Table 4. C-statistics for prediction of poor outcome and in-hospital mortality

\begin{tabular}{|c|c|c|c|c|c|}
\hline \multicolumn{3}{|c|}{ Poor outcome $(\mathrm{mRS}>2)^{a}$} & \multicolumn{3}{|c|}{ Death ${ }^{b}$} \\
\hline Characteristics & C-statistics $(95 \% \mathrm{CI})$ & $P^{*}$ & Characteristics & C-statistics $(95 \% \mathrm{CI})$ & $P^{*}$ \\
\hline NIHSS score $($ admission $) \geqq 12$ & $0.691(0.657-0.725)$ & & NIHSS score (admission) $\geqq 12$ & $0.790(0.707-0.872)$ & \\
\hline includes age $\geqq 76$ years & $0.748(0.717-0.780)$ & $<0.001$ & includes troponin $\mathrm{I}>0.01 \mathrm{ug} / \mathrm{L}$ & $0.860(0.799-0.921)$ & 0.001 \\
\hline further includes deterioration & $0.778(0.748-0.808)$ & $<0.001$ & further includes deterioration & $0.912(0.859-0.965)$ & 0.018 \\
\hline further includes troponin $\mathrm{I}>0.01 \mathrm{ug} / \mathrm{L}$ & $0.787(0.758-0.817)$ & 0.006 & further includes male gender & $0.926(0.884-0.969)$ & 0.134 \\
\hline further includes heart rate $\geqq 82 \mathrm{bpm}$ & $0.796(0.767-0.825)$ & 0.057 & & & \\
\hline Model 1 & $0.790(0.761-0.819)$ & $P^{* *}$ & Model 2 & $0.887(0.829-0.946)$ & $P^{* *}$ \\
\hline+ Troponin $\mathrm{I}>0.01 \mathrm{ug} / \mathrm{L}$ & $0.796(0.767-0.825)$ & 0.155 & + Troponin $\mathrm{I}>0.01 \mathrm{ug} / \mathrm{L}$ & $0.926(0.884-0.969)$ & 0.019 \\
\hline+ Troponin $\mathrm{I} \geqq 0.1 \mathrm{ug} / \mathrm{L}$ & $0.798(0.769-0.826)$ & 0.106 & + Troponin $\mathrm{I} \geqq 0.1 \mathrm{ug} / \mathrm{L}$ & $0.927(0.886-0.968)$ & 0.028 \\
\hline
\end{tabular}

544 Notes.

545 mRS, modified Rankin Scale; NIHSS, National Institute of Health Stroke Scale; CI, confidence interval; a multiple logistic regression; ${ }^{\mathrm{b}}$ stepwise backward

546 regression; * compared with previous one; ** compared with Model 1 or 2

547 Model 1 includes NIHSS score (admission) $\geqq 12$, age $\geqq 76$ years, deterioration, heart rate $\geqq 82 \mathrm{bpm}$

$548 \quad$ Model 2 includes NIHSS score (admission) $\geqq 12$, deterioration, male gender 